\title{
Is it ever ethical for doctors to diagnose patients they haven't examined?
}

\author{
n Cite as: CMAJ 2018 February 12;190:E175-6. doi: 10.1503/cmaj.109-5557
}

Posted on cmajnews.com on Jan. 23, 2018.

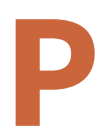

sychiatrists should never provide professional opinions in the media about public figures they have not personally examined, the American Psychiatric Association reiterated in a statement. The association was reminding members about what is known as "The Goldwater Rule" - a guideline penned in 1973 after more than 1000 psychiatrists went public with views about US presidential candidate Barry Goldwater's fitness to hold office, calling him, among other things, "a dangerous lunatic."

Despite this longstanding principle, however, many medical professionals have continued to weigh in over the years, particularly on the health of US presidents. Richard Nixon was declared "paranoid." Ronald Reagan was diagnosed from afar with Alzheimer disease. Bill Clinton was proclaimed a "narcissist." More recently, cardiologists had a field day with Donald Trump's cholesterol levels, belly fat and coronary calcium score.

At what point, if ever, should doctors go public with their from-a-distance diagnoses? Are psychiatrists unique, or are all doctors bound by the same covenant? What are the potential harms?

Last October, when a group of 27 mental health professionals, including psychiatrists, published a book arguing that the current US president's mental state was a danger to the nation, they said they were honouring another medical principle: the duty to warn. The idea behind "duty to warn" is that if you are in a position to know about a danger and have time to alert others, you should do so. Psychiatrists, for instance, are allowed to break doctor-patient confidentiality if they suspect a patient is about to harm a third party.

But part of that duty rests on having done a proper evaluation, according to Dr. David Goldbloom, a psychiatry professor and senior medical adviser for the Centre for Addiction and Mental Health. "You are intervening to abrogate fundamental civil freedoms," he said. "You can't do that from having read an article or watched television."

The Canadian Psychiatric Association said it has no official position on this subject. And although the American Psychiatric Association generally frowns on diagnoses made at a distance, there are instances

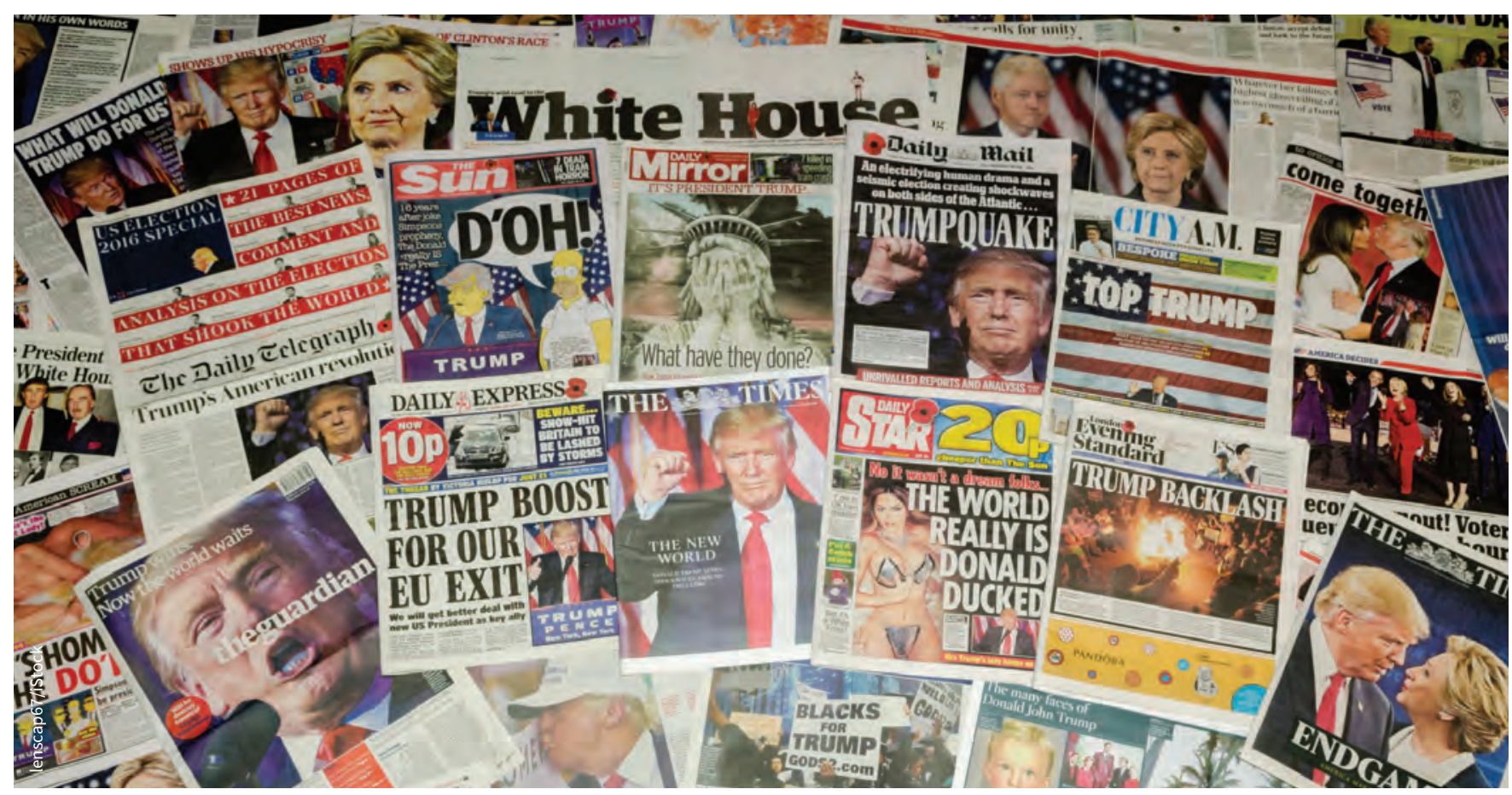

Physicians have been speculating in the media about US President Donald Trump's physical and mental health. 
when it's considered acceptable, noted Dr. Benoit Mulsant, chair of the department of psychiatry at the University of Toronto. For example, the Central Intelligence Agency will ask for psychiatric evaluations of world leaders who haven't been examined in person. Kim Jong-un's mental state has almost certainly been opined upon by psychiatrists, he said. When a judge requests a psychiatric assessment of a person whom the psychiatrist hasn't met, the assessment relies on materials collected by others. But in such cases, the limitations of the evaluations are understood, said Mulsant.

Other instances are more controversial, he said. He pointed to a recent case in Ontario, in which an optician discovered that a psychiatrist had rendered an opinion about his mental health without meeting or speaking with him. The evaluation was based solely on emails and a few documents. The optician learned of the report during a legal battle; his opponents had commissioned it. The College of Physicians and Surgeons of Ontario initially ruled that the physician's conduct was appropriate. On appeal, however, it said that the psychiatrist should not have released the findings to a third party without the patient's consent.

One reason for The Goldwater Rule is the likelihood of error in a diagnosis made at a distance. A proper diagnosis requires much more than "a review of television appearances, tweets, and public comments," the American Psychiatric Association noted in its statement. "The stan- dards in our profession require review of medical and psychiatric history and records and a complete examination of mental status. Often collateral information from family members or individuals who know the person well is included, with permission from the patient."

Armchair diagnosis can also harm trust in the medical profession, according to Brendan Leier, a clinical ethicist at the John Dossetor Health Ethics Centre. Doctors are stewards of an inherited trust. "What you do can undermine that trust," he said, because diagnosing public figures on cable TV could cause you to be perceived more as a political advocate than a physician.

Allison Motluk, Toronto, Ont. 